\title{
The Relationship between Force and the Temperature \& Length within one Cycle in Engine Cylinder
}

\author{
Run $\mathrm{xu}^{*}$ \\ Department of Metallurgical Engineering, Gyeongsang National University, Chinju 52828, Korea
}

DOI: $\underline{10.36348 / \text { sjet.2020.v05i11.010 }}$

| Received: 06.11.2020 | Accepted: 15.11.2020 | Published: 19.11.2020

*Corresponding author: Run $\mathrm{xu}$

\section{Abstract}

The force in engine is studied and find that the relationship of it and temperature with two methods of cooling and heating temperature. The force will decline when the temperature inclines in one cycle of engine cylinder movement. On the other hand force will incline when the temperature inclines with cooling temperature. When cylinder length inclines the force will decline.

Keywords: force; temperature; length; engine; cycle; cylinder; independent variable.

Copyright (C) 2020 The Author(s): This is an open-access article distributed under the terms of the Creative Commons Attribution 4.0 International License (CC BY-NC 4.0) which permits unrestricted use, distribution, and reproduction in any medium for non-commercial use provided the original author and source are credited.

\section{INTRODUCTION}

The fuel force is searched so that simulation is studied to find the relation of inflamer force to temperature and force in Engine is significant. Among them the force is important factor who determines driven capability, so it needs be studied to look for the internal their relation in vehicles. Through calculation the force in engine is successful so we can simulate it through engine cylinder [1-3]. Meantime the specified emitting is studied to find the quantity and allocation of fuel. The temperature may attain near two thousand ${ }^{\circ} \mathrm{C}$ which is studied in this paper details. In order to search these respects this paper is simulated and investigated. They are studied qualitatively before and after they are explosion and combustion in engine. It can result in many questions in engine. Meantime it has value to control and design more complicated cylinder according to it. To be benefit to our firm use the minimum gas may be investigated through engine as convenient for many quantitative vehicles. It is evaluated that one family has a vehicle ie. Mainly car in every three families. There are about three millions cars in Beijing city. So they are huge discharged gas especially to our environment. In this paper we discuss this fuel detail to search their discharged gas performance ie. Force. We look for this minimum gas method for environment and low cost for a certain force, which is destination.

The parameter of inflamer force is important at engine cylinder of vehicle. It is investigated that it is variable with temperature and cylinder length of one cycle in last paper [1,3]. It has significant role in structuring engine internal cylinder simulation and practical parameters. It is to evaluate the inflamer performance of force from cylinder which includes gas inflamer in whole in the end. It is convenient for us to control the inflamer and do the prediction and simulate status regardless of experimental measurement. It must connect with this measure later to check it's erring to be proven its precision. On the other hand it is investigated what the relationship between force and temperature $\&$ cylinder movement with length is. In this study the relationship between them is investigated detail for predicting cylinder performance.

\section{Modeling fuel of gasoline}

According to ideal gas principle formula

$d P d(1 / V)=N R T$

So $d P=N R T d(1 / V)(2)$

Here $d P=d F / S$

And $d V=D d L(4)$

Here, $\mathrm{T}$ is temperature $\mathrm{K} ; \mathrm{F}$ is force $\mathrm{N} ; \mathrm{S}$ is square of engine inner square, $\mathrm{m}^{2} ; \mathrm{d}$ is engine internal diameter $\mathrm{m} ; \mathrm{V}$ is volume of gas in engine, liters; $\mathrm{P}$ is gas pressure, $\mathrm{Pa} ; \mathrm{m}$ is gasoline mass, $\mathrm{Kg} ; 15$ is mass per mol.

\section{DISCUSSION}

According to formula above it is calculated the relational draw as below with different temperature and length in cylinder. Firstly it is F-T/L than independent 
Run xu; Saudi J Eng Technol, Nov, 2020; 5(11): 457-459

variable $\mathrm{L}$ and $\mathrm{T}$. Here $\mathrm{F}$ is force, $\mathrm{T}$ is temperature, and $\mathrm{L}$ is cylinder length in engine. We will state three relationships as below in detail. As for force in engine it is significant parameter to evaluate the vehicle performance. At design it will be proposed to prior matter to confirm and simulate. The basis principle is power which plays a significant role in loaded vehicle. If this parameter is not satisfied the others change to failure and void. The force is required to evaluate and confirm to by research and development (R\&D) whether or not to meet customer demand firstly.

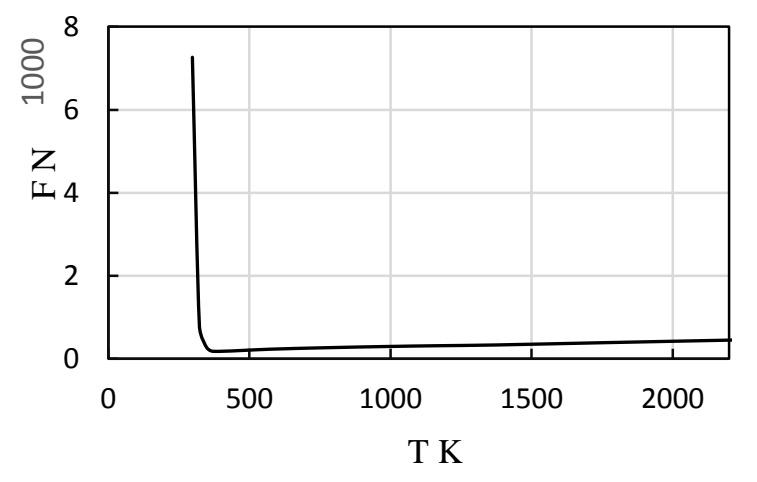

(a) Heating temperature

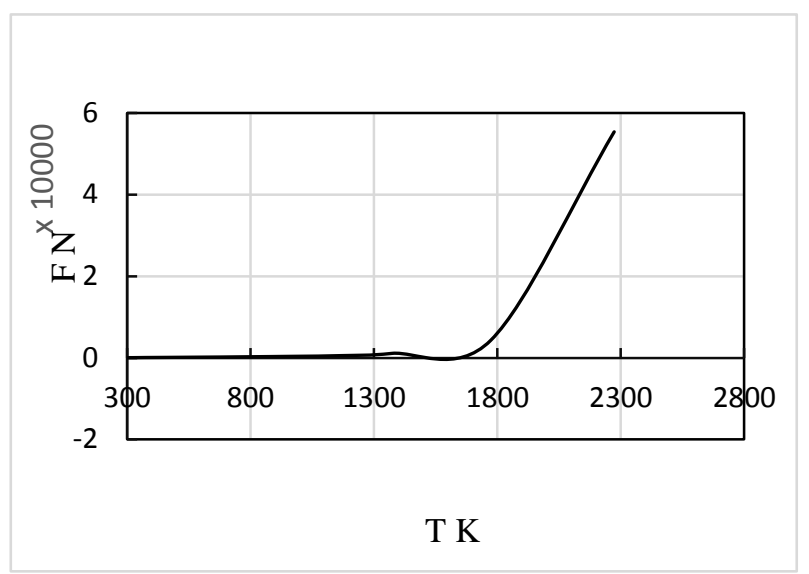

(b) Cooling temperature

Fig-1: Curve of force and different temperature in engine cylinder.

The force in engine is drawn and find that the relationship of it and temperature with two methods of cooling and heating temperature as seen in Figure 1(a,b). The force will decline when the temperature inclines. On the other hand force will incline when the temperature inclines with cooling temperature. When cylinder length inclines the force will decline as seen in Figure 2(a,b). It is declining trend in both of above two cases though it is main factor than $T$. Because the temperature is changed only not length in engine. There is so small effect at changed $\mathrm{T}$. the difference between them is higher in heating $\mathrm{T}$ than cooling $\mathrm{T}$ which arrives $7 \mathrm{KN}$ and $5.5 \mathrm{KN}$. This is a small difference which means temperature is neglected somewhat. So the turn of effect force $\mathrm{L}>\mathrm{T}$ is established in this paper. The curve steeply decrease at first zone of $1 \mathrm{~cm}$ both and them it maintain a line. The cooling temperature may keep a good case than the heating one which causes us to think whether this is a good performance. Because we can obtain better force at the cooling condition still that will decrease much cost and gasoline. The cooling course will be paid attention to too for dual win situation. In the future it shall be searched and studied further on this case to find more energy save condition and new design to maintain dual respects benefit. In Figure 1 as the length is not included so that temperature is variable. Though $\mathrm{L}>\mathrm{T}$ temperature is a factor here so the force exhibits opposition situation. Here $\mathrm{T}$ is becomes important factor to the force.

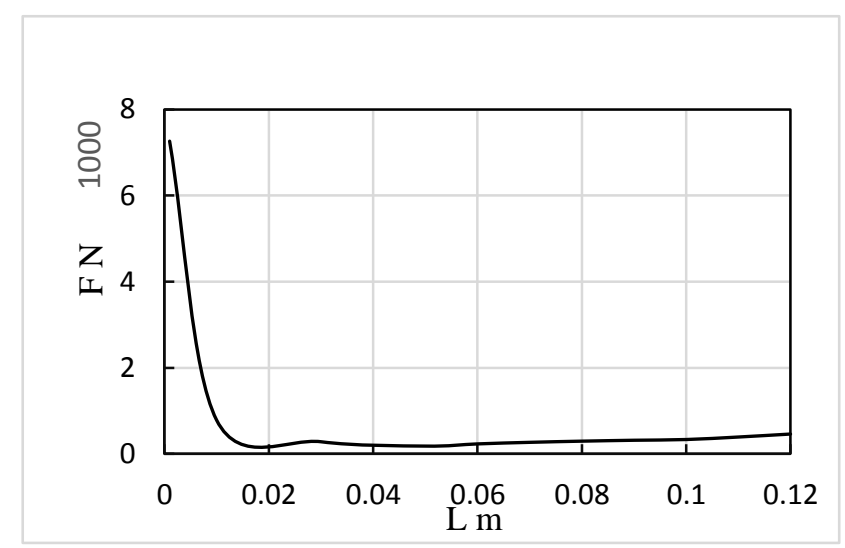

(a) Heating temperature

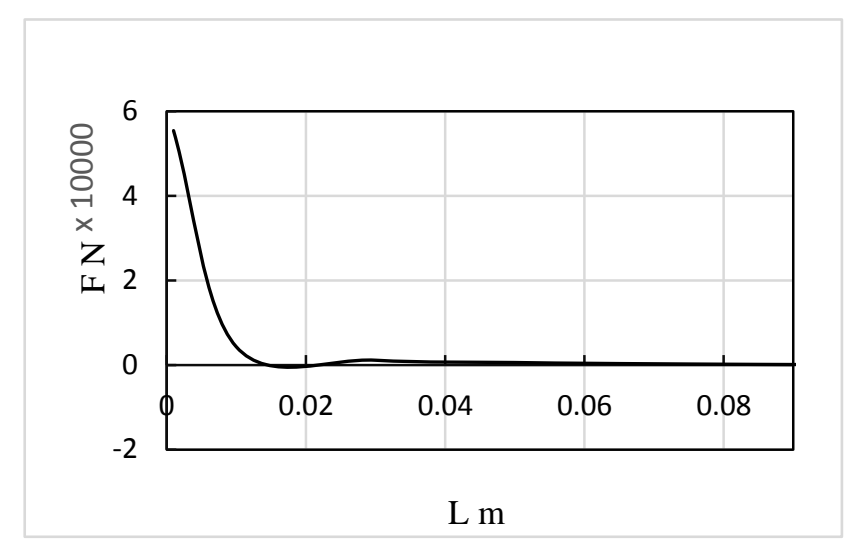

(b) Cooling temperature

Fig-2: Curve of force and length with different temperature in engine cylinder

The length in engine is important at the length of $2 \mathrm{~cm}$, after this length it is neglected with force. So the $\mathrm{L}<2 \mathrm{~cm}$ is the best condition. However at high temperature such as $2000 \mathrm{~K}$ the length plays a important effect too in terms of Figure 3(a). It is considered that the length wields its role in engine for its temperature increasing or it is not such a important parameter as mentioned above. 
Run xu; Saudi J Eng Technol, Nov, 2020; 5(11): 457-459

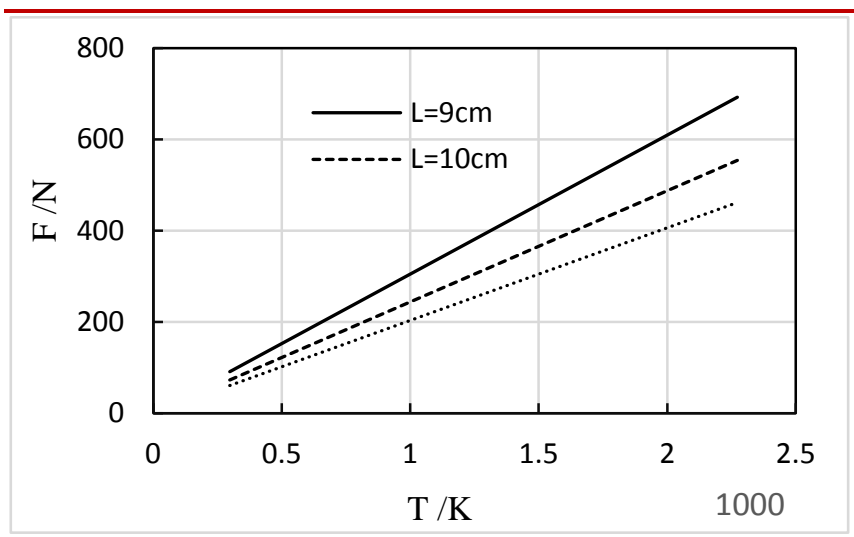

(a) Temperature in engine

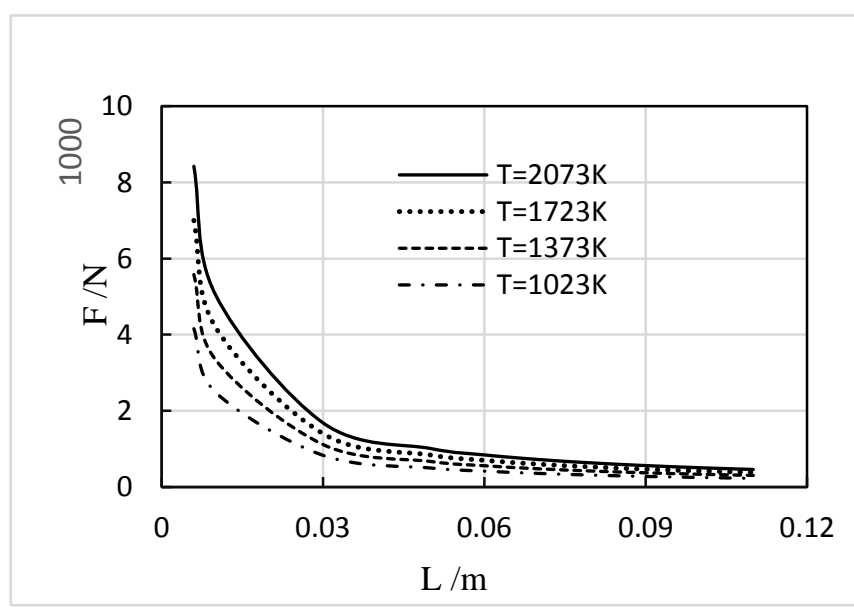

(b) Length in engine cylinder

Fig-3: The curves of force and temperature \&length with heating temperature in engine, $T$ is temperature, $L$ is cylinder length

With increasing temperature the force will increase proportionally as seen in Figure 3(a), meantime it has high force value with $600 \mathrm{~N}$ at low length of $9 \mathrm{~cm}$ at $2000 \mathrm{~K}$. The difference will incline with the increasing temperature. The force will decrease with increasing length in one cylinder cycle as seen in Figure 3 (b), meantime it has force of $7000 \mathrm{~N}$ with at length $1 \mathrm{~cm}$ and $1773 \mathrm{~K}$. The difference will be small along movement of length increasing. The force inclines with the increasing temperature. According to principle of $\mathrm{PV}=\mathrm{nRT}$, if volume $\mathrm{V}$ increases pressure $\mathrm{P}$ will decrease with maintaining temperature that is explanation. The force will converge on $0.5 \mathrm{E}+3 \mathrm{~N}$, ie $500 \mathrm{~N}$.

\section{CONCLUSIONS}

The force may decreases with temperature declining at heating temperature in one cycle of engine movement. Meantime it may be opposition at cooling temperature. The force will decline upon length increasingly. It has high force value with $600 \mathrm{~N}$ at low length of $9 \mathrm{~cm}$ at $2000 \mathrm{~K}$. Meantime it has force of $8000 \mathrm{~N}$ with at length $1 \mathrm{~cm}$ and $1773 \mathrm{~K}$. The force will decrease with increasing length and it inclines with the increasing temperature. The force will converge on $0.5 \mathrm{E}+3 \mathrm{~N}$, ie $500 \mathrm{~N}$.

\section{REFERENCES}

1. Run, X. (2020). Simulation of Harmful Fuel Inflamer through Outlet \& Maximum Pressure in Cylinder with Temperature in Engine of Vehicles. Saudi Journal of Engineering Technology, 5(10): 407-409.

2. Run, X. U. (2020). The Simulation of Dynamics and Consumed Fuel on Rotary Inertia of Vehicle. International Journal of Plant Engineering and Management, 25(2),1 12.

3. Shenghua, L., Longbao, Z. (2017). The Internal Combustion Engine to Learn, China Machine Press, 115-116. 